\title{
PROPERTIES OF CONCRETE INCORPORATING METAKAOLIN, FLYASH AND RECYCLED CONCRETE AGGREGATES
}

\author{
Shailja Bawa ${ }^{1}$, M. Singh ${ }^{2}$ \\ 1. Dr B R Ambedkar National Institute of Technology Jalandhar, India \\ 2. Dr B R Ambedkar National Institute of Technology Jalandhar, India \\ *Corresponding Author, email: bawas@ nitj.ac.in, mobile no.:+ \\ 918283821380
}

\begin{abstract}
This work is carried out on the use of metakaolin as a partial replacement for Ordinary Portland Cement along with flyash and replacement of coarse natural aggregates with recycled concrete aggregates of varying sizes. The natural aggregates were replaced up to $75 \%$ by recycled concrete aggregates obtained from Construction and Demolishing (C\&D) wastes after breaking them into two types of sizes, $4.75 \mathrm{~mm}$ $10 \mathrm{~mm}$ and $10-12.5 \mathrm{~mm}$. The fly ash was used as partial replacement of cement by $30 \%$ in reference mix. Then $10 \%$ metakaolin was introduced reducing flyash to $20 \%$. Total 162 cubes and 54 beam specimen were cast for testing. The mix with natural aggregates gained maximum strength results in compressive, split tensile and flexural strength tests at all ages. But, it was observed that mineral admixtures such as metakaolin can easily compensate the loss of strength due to addition of recycled aggregates as well as improve workability and other properties.
\end{abstract}

Keywords: Recycled aggregates, Mechanical properties, Sustainable concrete

\section{INTRODUCTION}

Rapid rate of urbanization in India because of industrialization requires an extensive amount of construction materials. At the same time, the exhaustion of natural construction materials and disposal of huge quantity of wastes from industries and construction and demolition are of major concern. Near about one billion tons of demolition waste is created in a year in the world. There are clear advantages of using this demolition waste as natural aggregates than to send them to landfills [1]. Recycled aggregates are composite materials framed from cement, aggregates, water, admixtures and halfway cement replacement materials. Full substitution of natural aggregates with recycled concrete aggregates in concrete is even permitted in few nations in specific circumstances [2]. Professionals in the construction and demolition industry Besides from this perspective, use of industrial wastes may give us ecological benefits [3]. The use of flyash as cement replacement results in lesser release of carbon di oxide and lower rate of temperature alterations in universe. Metakaoline has been 
found to show the positive effect on the strength of concrete after 2 days and specifically at 28 and 180 days. It also increases the sulphate resistance of cement [4]. This investigation is carried out to study the mechanical properties of concrete using metakaolin as a partial replacement for Ordinary Portland Cement along with flyash and replacement of coarse natural aggregates with recycled concrete aggregates of varying sizes.

\section{EXPERIMENTAL PROGRAM}

\subsection{Material Properties}

The properties of materials used in concrete have been determined in laboratory as per relevant code of practice. Ordinary Portland Cement (OPC) of 43 Grade was used for all concrete mixes. Two types of coarse aggregates $(4.75 \mathrm{~mm}-10 \mathrm{~mm} \& 10 \mathrm{~mm}-$ $12.5 \mathrm{~mm}$ ) were used in the mixes in different proportions. . Locally available river bed sand was used in the present study. The sand conforms to grading Zone - III as per IS: $383-1970$ respectively. Two types of recycled aggregates were used in the mixes in different proportions:

* CA - I Recycled Concrete Aggregates passing $10 \mathrm{~mm}$ sieve and retained on $4.75 \mathrm{~mm}$ sieve.

* CA - II Recycled Concrete Aggregates passing $12.5 \mathrm{~mm}$ sieve and retained on $10 \mathrm{~mm}$ sieve.

The recycled aggregates used were washed to remove dust and dirt and were dried to surface dry condition. Specific gravity of Coarse Natural Aggregates was found to be 2.64 whereas specific gravity of Recycled concrete aggregates came to be 2.46 . The value of weight of recycled concrete aggregates to be replaced with natural aggregates was calculated after multiplying with factor of 0.93 , which was calculated from equivalent value approach i.e 2.46/2.64 $=0.93$.

Metakaolin METACEM $85 \mathrm{C}$ was used in the current investigation. It was procured from 20 microns Limited, Vadodara, India. Water used for mixing and curing was clean and free from injurious amounts of oils, acids, alkalies, salts and sugar, organic materials or other substances that may be deleterious to concrete.

\subsection{Mix Combinations}

Table 1 represents the details about the different mixes to be used by weight per cubic metre. M1 mix as shown in table 2 above has been considered as reference mix in which fly ash was used as a replacement of cement by $30 \%$. Sand \& Natural coarse aggregates were used as mentioned above, whereas no Recycled coarse aggregates were used in this mix. The water cement ratio in all the mixes was taken as 0.4 . In Mixes M2 to M5, Natural coarse aggregates were replaced with Recycled concrete aggregates of varying sizes i.e. $4.75 \mathrm{~mm}$ to $10 \mathrm{~mm}$ and $10 \mathrm{~mm}$ to $12.5 \mathrm{~mm}$ in the ratio of $50 \%$ and $75 \%$. These mixes were cast to study the effects of replacement of natural aggregates with recycled concrete aggregates on strength properties. 
Table 1. Details of Batches (Mix Wise)

\begin{tabular}{|c|c|c|c|c|c|c|c|c|}
\hline \multirow[t]{2}{*}{ Mix } & \multirow{2}{*}{$\begin{array}{c}\text { OPC } \\
(\mathbf{k g})\end{array}$} & \multirow{2}{*}{$\begin{array}{l}\text { Fly } \\
\text { Ash } \\
\text { (kg) }\end{array}$} & \multirow{2}{*}{$\begin{array}{l}\text { Meta } \\
\text { kaoli } \\
\text { n (kg) }\end{array}$} & \multirow{2}{*}{$\begin{array}{c}\text { Sand } \\
\text { (kg) }\end{array}$} & \multirow{2}{*}{$\begin{array}{c}\text { Coarse } \\
\text { Natural } \\
\text { Aggregate } \\
\text { s (kg) }\end{array}$} & \multicolumn{2}{|c|}{ RCA (kg) } & \multirow{2}{*}{$\begin{array}{c}\text { Water } \\
\text { (kg) }\end{array}$} \\
\hline & & & & & & $\begin{array}{l}4.75- \\
10 \\
\mathrm{~mm}\end{array}$ & $\begin{array}{l}10- \\
12.5 \\
\mathrm{~mm}\end{array}$ & \\
\hline M1 & 13.52 & 5.80 & 0 & 28.61 & 36.34 & 0 & 0 & 7.73 \\
\hline M2 & 13.52 & 5.80 & 0 & 28.61 & 18.22 & 16.93 & 0 & 7.73 \\
\hline M3 & 13.52 & 5.80 & 0 & 28.61 & 18.22 & 0 & 16.93 & 7.73 \\
\hline M4 & 13.52 & 5.80 & 0 & 28.61 & 9.11 & 0 & 25.39 & 7.73 \\
\hline M5 & 13.52 & 5.80 & 0 & 28.61 & 9.11 & 25.39 & 0 & 7.73 \\
\hline M6 & 13.52 & 3.86 & 1.93 & 28.61 & 18.22 & 16.93 & 0 & 7.73 \\
\hline M7 & 13.52 & 3.86 & 1.93 & 28.61 & 18.22 & 0 & 16.93 & 7.73 \\
\hline M8 & 13.52 & 3.86 & 1.93 & 28.61 & 9.11 & 0 & 25.39 & 7.73 \\
\hline M9 & 13.52 & 3.86 & 1.93 & 28.61 & 9.11 & 25.39 & 0 & 7.73 \\
\hline
\end{tabular}

In Mixes M6 to M9, Metakaolin was introduced in addition to fly ash in the mix by using $70 \%$ Cement, $20 \%$ fly ash and 10\% Metakaolin. Natural coarse aggregates were replaced with Recycled concrete aggregates of varying sizes i.e $4.75 \mathrm{~mm}$ to $10 \mathrm{~mm}$ and $10 \mathrm{~mm}$ to $12.5 \mathrm{~mm}$ in the ratio of $50 \%$ and $75 \%$, same as in case of mixes M2 to M5 .These mixes were cast to study effects of replacement of natural aggregates with recycled concrete aggregates with addition of Metakaolin along with fly ash in the concrete.

Compressive strength tests and split tensile strength were conducted on concrete cubes of size $100 \mathrm{~mm} \times 100 \mathrm{~mm} \times 100 \mathrm{~mm}$ cast from concrete of each mix sample after 7, 28 and 56 days of curing. These tests were carried out in accordance with IS: 516-1959 on Compression Testing Machine. The average of three samples was taken as the representative value of compressive strength. To determine flexural strength of beams, beams of size $500 \times 100 \times 100 \mathrm{~mm}$ size were casted and were tested after 28 and 56 days of curing of samples.

\section{RESULTS AND DISCUSSION}

\subsection{Compressive Strength}

The compressive strength of M1 mix (reference mix), is maximum among all the mixes. The compressive strength of the mixes M2, M3, M4 \& M5 decreased with addition of RCA of 4.75-10 mm size and 10-12.5 mm size, replacing Natural Aggregates partially by 50\% in M2 \& M3 and 75\% in M4 \& M5 as shown in Table 2. It was noticed that the compressive strength of mixes casted with $4.75-10 \mathrm{~mm}$ recycled aggregate was more in comparison to mixes casted with $10-12.5 \mathrm{~mm}$ recycled aggregates.

Mixes M6 to M9 were casted with addition of $10 \%$ Metakaolin in replacement to Fly Ash used in existing mixes M2 to M5. Similar trends of all the strengths were noticed 
in these mixes but the magnitude of Compressive, Split Tensile \& Flexural strengths of the mixes increased with its addition.

Mix M6 among the RCA mixes has shown optimum strength with 10\% Metakaolin, $20 \%$ fly ash and $70 \%$ Cement content as binder material. The values of compressive strength at age 7 days, 28 days \& 56 days have been plotted in the graph as shown in Fig. 1.

Table 2. Compressive Strength Results

\begin{tabular}{|lccc|}
\hline Mix & 7-Day (MPa) & 28-Day (MPa) & 56-Day (MPa) \\
\hline M1 & 32.83 & 42.55 & 45.85 \\
\hline M2 & 28.98 & 40.12 & 42.21 \\
\hline M3 & 26.85 & 38.85 & 41.87 \\
\hline M4 & 24.54 & 34.40 & 38.15 \\
\hline M5 & 25.11 & 37.40 & 39.12 \\
\hline M6 & 30.95 & 40.75 & 43.90 \\
\hline M7 & 27.14 & 39.24 & 42.40 \\
\hline M8 & 26.66 & 35.29 & 39.95 \\
\hline M9 & 26.90 & 38.55 & 41.45 \\
\hline
\end{tabular}

It was noticed that the compressive strength of mixes casted with 4.75-10mm Recycled aggregate was more in comparison to mixes casted with $10-12.5 \mathrm{~mm}$ Recycled aggregates. Mixes M6 to M9 were cast with addition of $10 \%$ Metakaolin in replacement to Fly Ash used in existing mixes M2 to M5. Mix M6 among the RCA mixes has shown optimum strength with $10 \%$ Metakaolin, $20 \%$ fly ash and $70 \%$ Cement content as binder material.

The trends of compressive strengths at different ages of concrete can be analyzed from From Fig.1. It can be easily noticed that 7 day strengths have sharply declined in mixes M1 to M4 with little increase in M5 whereas a steep rise is seen in mix M6 followed by decreasing strengths upto mix M8 and a marginal increase in M9. Similarly at the age of 28 days a marginal decline has been seen in mixes M1 to M3 and sharp decline in M4, considerable increase in M5, followed by increase again in M6 and decrease in strengths up to M8 followed by a considerable rise in M9. In 56 days strengths, marginal increase has been seen from 28 days strengths with almost comparable trends. 


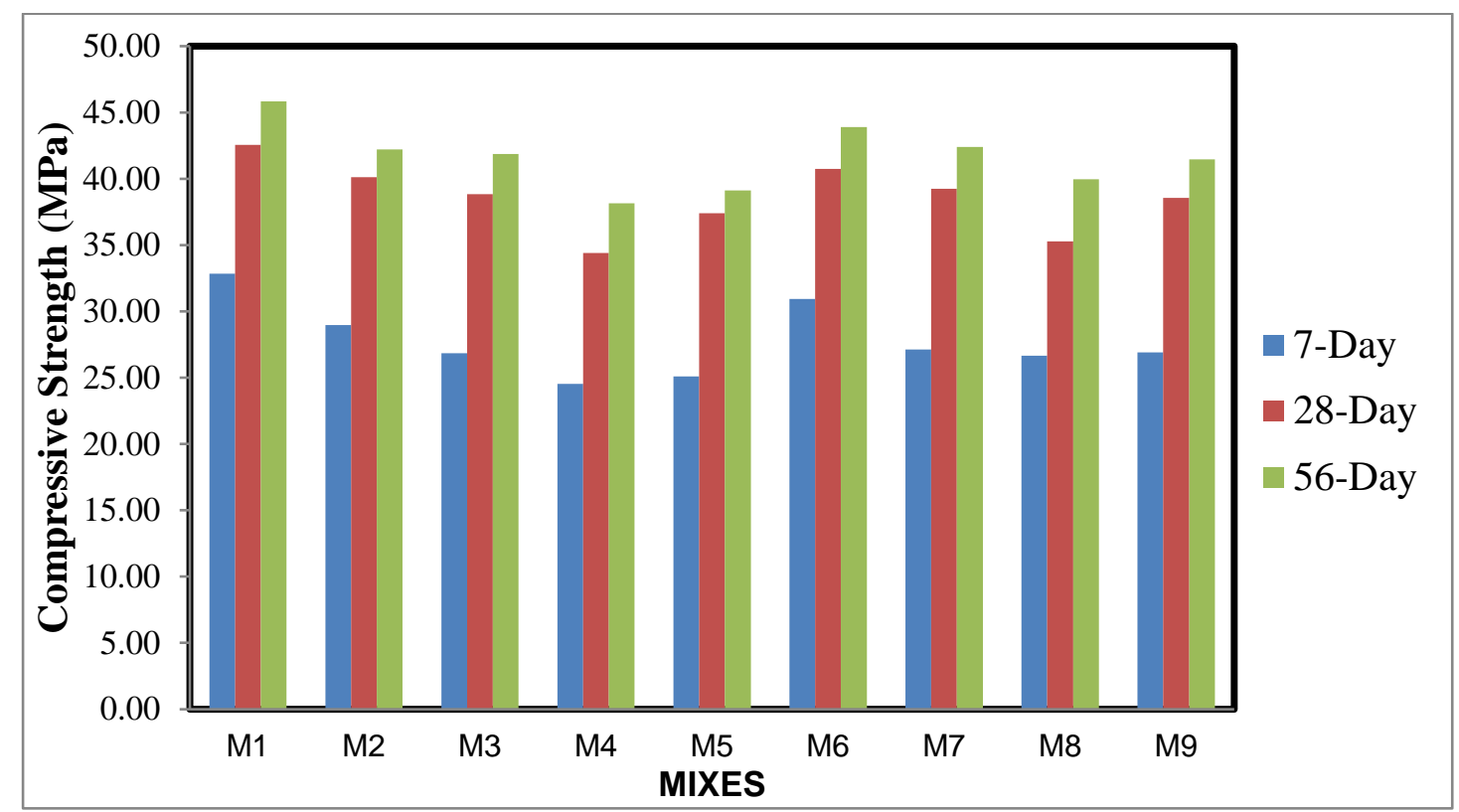

Fig. 1. Compressive Strength of all the mixes at $7,28, \& 56^{\text {th }}$ day of curing

\subsection{Splitting Tensile Strength}

As per the results in Table 3, splitting tensile results followed similar trends as of compressive strength results. Mix M1 as reference mix has shown the maximum splitting tensile strength. Whereas, mix M6 with 10\% Metakaolin in 50\% coarse natural aggregates and $50 \%$ recycled concrete aggregates mix has shown comparably higher splitting tensile strength than all other mixes. Similarly mixes M6-M9 with 10\% Metakaolin gave comparatively higher splitting tensile strengths than other RCA mixes M2-M4. This could be due to the fact that Metakaolin enhanced the strengths of RCA mixes at different levels of grading of aggregates.

Table 3. Splitting Tensile Strength Results

\begin{tabular}{|lccc|}
\hline Mix & 7-Day (MPa) & 28-Day (MPa) & 56-Day (MPa) \\
\hline M1 & 2.91 & 5.55 & 5.90 \\
\hline M2 & 2.52 & 4.91 & 5.16 \\
\hline M3 & 2.10 & 4.12 & 4.84 \\
\hline M4 & 1.61 & 3.77 & 4.26 \\
\hline M5 & 1.57 & 4.10 & 4.49 \\
\hline M6 & 2.59 & 5.12 & 5.52 \\
\hline M7 & 2.11 & 4.96 & 5.28 \\
\hline M8 & 1.52 & 3.84 & 4.31 \\
\hline M9 & 1.69 & 4.11 & 4.74 \\
\hline
\end{tabular}




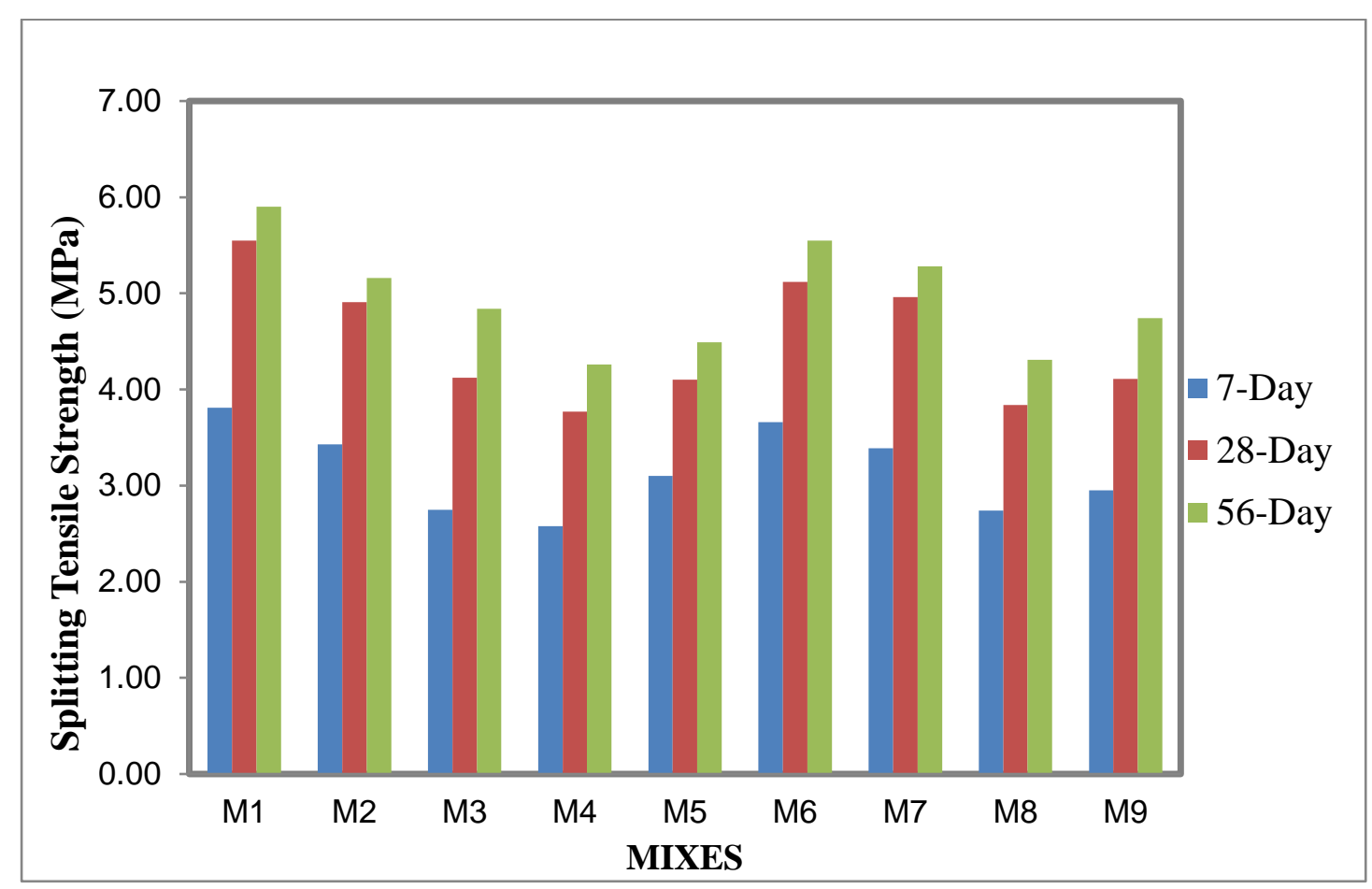

Fig. 2 Splitting Tensile Strengths of all the mixes at $7,28, \& 56^{\text {th }}$ day of curing

The trends of Splitting Tensile strengths at different ages of concrete can be analyzed from Fig. 2. It can be noticed that 7 day strengths have declined in mixes M1 to M4, with little increase in M5 whereas a steep rise is seen in mix M6 followed by decreasing strengths upto mix M8 and a marginal increase in M9. Similarly at the age of 28 days considerable decline has been seen in mixes M1 to M4, with little increase in M5, followed by increase again in M6 and decrease in strengths upto M8, followed by a considerable rise in M9. In 56 days strengths, marginal increase has been seen from 28 days strengths with almost similar trends.

\subsection{Flexural Strength}

Flexural strength results were seen at the age of 28 days \& 56 days in different mixes as per Table 4. Flexural strength results followed similar trends as of compressive strength \& split tensile strength results. Mix M1 as reference mix has shown the maximum flexural strength. Whereas, the mix M6 with $10 \%$ metakaolin in 50\% coarse natural aggregates and $50 \%$ recycled concrete aggregates mix has shown the comparably higher flexural strength than other mixes. Similarly mixes M6 and M9 with 10\% Metakaolin gave comparatively higher flexural strengths than other RCA mixes. This could be due to the fact that Metakaolin enhanced the strengths of RCA mixes at different levels of grading of aggregates.

The trends of Flexural strengths at different ages of concrete can be analysed from Fig. 3. It can be noticed that 28 day strengths have declined in mixes M1 to M4, with little increase in M5 whereas a steep rise is seen in mix M6 followed by decreasing strengths upto mix M8 and a marginal increase in M9. Similarly at the age of 56 days considerable decline has been seen in mixes M1 to M4, with little increase in M5, 
followed by increase again in M6 and decrease in strengths upto M8, followed by a considerable rise in M9.

Table 4. Flexural Strength Results

\begin{tabular}{|lcc|}
\hline Mix & 28-Day (MPa) & 56-Day (MPa) \\
\hline M1 & 7.55 & 8.45 \\
\hline M2 & 6.74 & 7.34 \\
\hline M3 & 5.80 & 6.28 \\
\hline M4 & 5.15 & 5.81 \\
\hline M5 & 5.46 & 5.98 \\
\hline M6 & 6.80 & 7.42 \\
\hline M7 & 5.92 & 6.32 \\
\hline M8 & 5.49 & 5.98 \\
\hline M9 & 5.61 & 6.07 \\
\hline
\end{tabular}

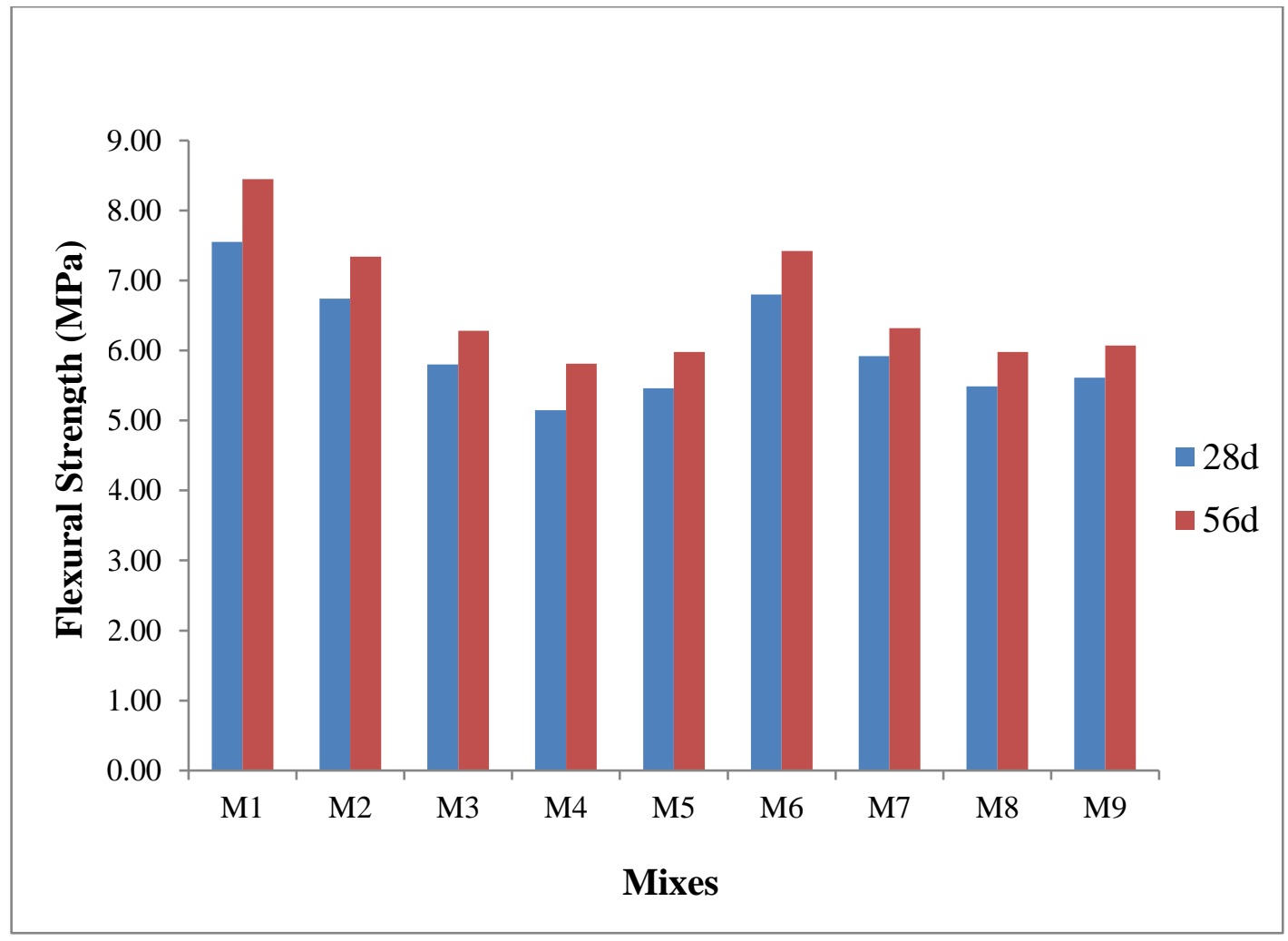

Fig. 3. Flexural Strength Results at the age of $28 \& 56$ days of curing 


\section{ANALYSIS OF RESULTS}

To analyse more, the relations between different strengths of the mixes were studied thoroughly and their results were compared after plotting in various graphs. To generate the relationship between compressive and splitting tensile strengths for the various mixes in our study, graphs were plotted for different mixes at the ages of 28 days \& 56 days and binary equation of relationship was established between compressive and split tensile strengths. Similar relationships between compressive strength and flexural strength have been established. The equations obtained have been summarized in Table 5.

Table 5. Relationship established between Compressive strength, Split tensile strength and Flexural strength

\begin{tabular}{|c|c|c|c|}
\hline Mix Combinations & Mix ID's & $\begin{array}{l}\text { Relationship } \\
\text { Obtained } \\
\text { (28 Days) }\end{array}$ & $\begin{array}{l}\text { Relationship } \\
\text { Obtained } \\
\text { (56 Days) }\end{array}$ \\
\hline $\begin{array}{l}\text { Splitting } \\
\text { Results for Mixile } \\
\text { without Metakaolin }\end{array}$ & $\begin{array}{l}\text { M1 } \\
\text { M2 } \\
\text { M3 } \\
\text { M4 } \\
\text { M5 }\end{array}$ & $f_{\text {ct }}=0.158 f_{c k}-1.236$ & $f_{c t}=0.149 f_{c k}-1.035$ \\
\hline $\begin{array}{l}\text { Splitting Tensile } \\
\text { Results for Mixes with } \\
\text { Metakaolin }\end{array}$ & $\begin{array}{l}\text { M1 } \\
\text { M6 } \\
\text { M7 } \\
\text { M8 } \\
\text { M9 }\end{array}$ & $f_{\text {ct }}=0.188 f_{c k}-2.491$ & $\mathrm{f}_{\mathrm{ct}}=0.152 \mathrm{f}_{\mathrm{ck}}-1.244$ \\
\hline $\begin{array}{l}\text { Flexural Strength } \\
\text { Results for Mixes } \\
\text { without Metakaolin. }\end{array}$ & $\begin{array}{l}\text { M1 } \\
\text { M2 } \\
\text { M3 } \\
\text { M4 } \\
\text { M5 }\end{array}$ & $f_{y}=0.185 f_{c k}-2.217$ & $f_{y}=0.163 f_{c k}-1.707$ \\
\hline $\begin{array}{l}\text { Flexural Strength } \\
\text { Results for Mixes with } \\
\text { Metakaolin. }\end{array}$ & $\begin{array}{l}\text { M1 } \\
\text { M6 } \\
\text { M7 } \\
\text { M8 } \\
\text { 99 }\end{array}$ & $f_{y}=0.211 f_{c k}-3.485$ & $f_{y}=0.176 f_{c k}-2.314$ \\
\hline
\end{tabular}




\section{CONCLUSION}

The Compressive, Splitting Tensile \& Flexural strengths of the mixes was found to decrease with increase in percentage of Recycled aggregates. The addition of Metakaolin in the mixes was found to increase the Compressive, Splitting as well as the flexural strength of various mixes. The mix with $10 \%$ replacement of cement with Metakaolin \& $20 \%$ with fly ash as a binder material shows the maximum increase in the compressive, Splitting tensile strength as well as flexural strength of the mixes. The early age strength of the various combinations of Metakaolin and fly ash was found to be more than the later age strength. The percentage reduction in strength can be decreased further by increasing the percentage of Metakaolin and reducing the percentage of RCA in the concrete.

\section{REFERENCES}

Coelho, A., De Brito, J. (2011), “Economic analysis of conventional versus selective demolition- a case study”, Resour Conserv Recycle, 55 (3), 382 - 392.

Evangelista, L., Guedes, M., De Brito J., Ferro A. C., Pereira M. F. (2015), "Physical, chemical and mineralogical properties of fine recycled aggregates made from concrete waste", Construction and Building Materials, 86, 178 - 188.

Roussat, N., Dujet, C., Mehu, J.(2009), "Choosing a sustainable demolition waste management strategy using multicriteria decision analysis" Waste Manage, Oxford, $29,12-20$.

Al-Akhras, N. M. (2006), "Durability of metakaolin concrete to sulphate attack", Cement and Concrete Research, 36 (9), 1727 - 1734. 